\title{
ANALISIS PERBEDAAN VARIABEL PENENTU KINERJA BIDAN DALAM MENGELOLA DESA / KELURAHAN SIAGA AKTIF BERSTRATA PURI DAN NON PURI DI KABUPATEN LUMAJANG TAHUN 2018
}

\section{Differences Analysis of Midwives job Performance Managing Desa/Kelurahan Siaga Aktif with Puri Strata and Non Strata in Lumajang Regency 2018}

\author{
Ratna Vitasari*, Yennike Tri Herawati, Mury Ririanty \\ Fakultas Kesehatan Masyarakat Universitas Jember \\ *e-mail korespondensi: ratnavitasari9@gmail.com
}

\begin{abstract}
In Lumajang Regency, the coverage of Desa dan Kelurahan Siaga Aktif Puri in 2018 around 15\% out $70 \%$ target set. The active performance of midwives in development of Desa dan Kelurahan Siaga Aktif is highly expected. They have a role in managing Desa dan Kelurahan Siaga Aktif. This study was a quantitative study aimed to analysis differences of midwives job performance managing desa/kelurahan siaga aktif with puri strata and Non puri strata in Lumajang Regency 2018. The results showed there was significantly different between Desa and Kelurahan Siaga Aktif with Puri Strata and non Puri in Lumajang Regency among facilities and infrastructure $(p=0,000)$, training $(p=0.004)$ and community support $(p=0,000)$ There was no difference between knowledge variables $(p=0.107)$, years of service $(p$ $=0.483)$, domicile $(p=0.546)$, intrinsic motivation $(p=0.756)$, extrinsic motivation $(p=0.151)$, supervision $(p=0.660)$, midwife performance $(p=0.105)$ with strata of Desa dan Kelurahan Siaga Aktif Puri with non Puri in Lumajang Regency. It can be concluded midwives among Desa dan Kelurahan Siaga Aktif strata Puri have different facilities and infrastructure, training, community support from the midwives Desa and Kelurahan Siaga Aktif strata non Puri.
\end{abstract}

Keywords: midwife performance, Desa Siaga

\begin{abstract}
Abstrak
Cakupan Desa dan Kelurahan Siaga Aktif Puri di Kabupaten Lumajang Tahun 2018 adalah 15\% dari $70 \%$ target yang di tetapkan. Keaktifan bidan desa dalam pengembangan Desa dan kelurahan Siaga Aktif sangat diharapkan karena bidan desa memiliki peran dalam mengelola Desa dan kelurahan Siaga Aktif. Penelitian ini merupakan penelitian kuantitatif yang bertujuan untuk menganalisis perbedaan variabel kinerja bidan dalam mengelola Desa dan Kelurahan Siaga Aktif berstrata Puri dengan belum Puri di Kabupaten Lumajang Tahun 2018. Hasil penelitian menunjukkan bahwa variabel yang berbeda antara Desa dan Kelurahan Siaga Aktif berstrata Puri dengan yang belum mempunyai strata Puri yaitu sarana dan prasarana $(p=0,000)$, pelatihan $(p=0,004)$ dan dukungan masyarakat $(p=0,000)$. Tidak ada perbedaan antara variabel pengetahuan $(p=0,107)$, masa kerja $(p=0,483)$, domisili $(p=0,546)$, motivasi intrinsik $(p=0,756)$, motivasi ekstrinsik $(p=0,151)$,supervisi $(p=0,660)$, kinerja bidan $(p=0,105)$ dengan strata Desa dan Kelurahan Siaga Aktif Puri dengan belum Puri di Kabupaten Lumajang. Bidan Desa dan Kelurahan Siaga Aktif berstrata Puri memiliki perbedaan sarana dan prasarana, pelatihan, dukungan masyarakat dengan bidan Desa dan Kelurahan Siaga Aktif belum Puri.
\end{abstract}

Kata Kunci : Kinerja bidan, Desa Siaga 


\section{PENDAHULUAN}

Upaya untuk mencapai derajat kesehatan masyarakat yang setinggi-tingginya melalui pembangunan kesehatan diarahkan untuk meningkatkan kesadaran, kemauan, dan kemampuan hidup sehat bagi setiap orang (UU RI, 2009). Pembangunan kesehatan diarahkan kepada beberapa hal prioritas. Salah satu strategi ditetapkan berdasarkan Keputusan Menteri Kesehatan Republik Indonesia Nomor 1529/MENKES/SK/X/2010 yaitu pemerintah membentuk program Desa dan Kelurahan Siaga Aktif yang memiliki komponen pelayanan kesehatan dasar, pemberdayaan masyarakat melalui pengembangan Upaya Kesehatan Bersumberdaya Masyarakat (UKBM) dan mendorong upaya survailans berbasis masyarakat, kedaruratan kesehatan dan penanggulangan bencana serta penyehatan lingkungan, serta Perilaku Hidup Bersih dan Sehat (PHBS). Desa dan Kelurahan Siaga Aktif merupakan desa atau yang disebut dengan nama lain kelurahan yang penduduknya dapat mengakses dengan mudah pelayanan kesehatan dasar yang memberikan pelayanan setiap hari melalui Pos Kesehatan Desa (Poskesdes), Pusat Kesehatan Masyarakat Pembantu (Pustu), Pusat Kesehatan Masyarakat (Puskesmas) atau sarana kesehatan lainnya, selain itu penduduknya mengembangkan UKBM dan melaksanakan survailans berbasis masyarakat, kedaruratan kesehatan dan penanggulangan bencana, serta penyehatan lingkungan sehingga masyarakatnya menerapkan Perilaku Hidup Bersih dan Sehat (PHBS) (KMK RI, 2010).

Target kinerja program Desa/ Kelurahan Siaga Aktif berstrata Puri tahun 2017 Dinas Kesehatan Provinsi Jawa Timur yaitu 70\%. Capaian Desa /Kelurahan Siaga Aktif berstrata purnama dan mandiri tahun 2017 berturut-turut 1.287 desa (24\%) dan 189 desa (2,3\%). Total Desa dan Kelurahan Siaga Aktif Puri tahun 2017 yaitu 1.476 Desa atau sebesar 17,8\% (Dinkes Jatim, 2017). Artinya, target kinerja program Desa dan Kelurahan Siaga Aktif berstrata Puri tahun 2017 belum tercapai.
Berdasarkan data Desa dan Kelurahan Siaga Aktif Dinas Kesehatan Kabupaten Lumajang Tahun 2017 telah mencapai 100\% yakni total 205 desa dan kelurahan. Jumlah Desa dan Kelurahan Siaga Aktif berstrata Puri tahun 2017 yaitu 20 (10\%) desa dan kelurahan sedangkan jumlah Desa dan Kelurahan Siaga Aktif belum Puri yaitu 185 (90\%) desa dan kelurahan. Jumlah Desa dan Kelurahan Siaga Aktif berstrata Puri tahun 2018 yaitu 32 (15\%) desa dan kelurahan sedangkan jumlah Desa dan Kelurahan Siaga Aktif belum Puri yaitu 173 (85\%) desa dan kelurahan (Dinkes Lumajang, 2017). Artinya capaian Desa dan Kelurahan Siaga Aktif berstrata Puri masih jauh dari indikator kinerja Dinas Kesehatan Jawa Timur.

Penelitian ini bertujuan untuk menganalisis perbedaan variabel kinerja bidan dalam mengelola Desa dan Kelurahan Siaga Aktif berstrata Puri dengan belum Puri di Kabupaten Lumajang Tahun 2018.

\section{METODE PENELITIAN}

Jenis penelitian ini merupakan penelitian kuantitatif dengan desain cross sectional dan dilakukan di Desa dan Kelurahan Siaga Aktif Kabupaten Lumajang. Penentuan responden penelitian dilakukan dengan menggunakan teknik simple random sampling dengan jumlah 31 bidan Desa / Kelurahan Siaga Aktif berstrata Puri dan 85 bidan desa dan Kelurahan Siaga Aktif belum Puri. Teknik pengumpulan data yaitu berupa wawancara, observasi dan dokumentasi.

Variabel penelitian yaitu pengetahuan, masa kerja, domisili, motivasi, sarana dan prasarana, pelatihan, dukungan masyarakat danz strata Desa/ Kelurahan Siaga Aktif Puri dan belum Puri. Teknik analisis data dalam penelitian ini dilakukan menggunakan analisis bivariat dengan bantuan program pengolah statistik. Penelitian ini menggunakan analisis bivariat dengan uji chi square.

\section{HASIL DAN PEMBAHASAN}

\section{Hasil}

Berdasarkan Tabel 1 dapat diketahui bahwa $p$ value variable pengetahuan sebesar 0,107 atau lebih besar dari $(0,05)$ yang berarti Ho diterima. Tidak terdapat perbedaan antara pengetahuan bidan di Desa/Kelurahan Siaga Aktif berstrata Puri dengan yang belum berstrata Puri di Kabupaten Lumajang tahun 2018. 
Tabel 1. Pengetahuan Bidan Desa

\begin{tabular}{lccccc}
\hline Pengetahuan & \multicolumn{4}{c}{$\begin{array}{c}\text { Strata Desa dan } \\
\text { Kelurahan Siaga Aktif } \\
\text { Belum }\end{array}$} & $\begin{array}{c}\boldsymbol{p} \text { - } \\
\text { value }\end{array}$ \\
& $\begin{array}{c}\text { Puri } \\
\text { Puri }\end{array}$ & & & \\
& N & N & N & \% & \\
\hline Rendah & 8 & 100 & 0 & 0,0 & $\mathbf{0 , 1 0 7}$ \\
Tinggi & 77 & 71,3 & 31 & 28,7 & \\
\hline
\end{tabular}

Berdasarkan tabel 2 dapat diketahui $p$ value masa kerja 0,483 atau $>(0,05)$, maka keputusannya terima Ho atau tidak terdapat perbedaan antara masa kerja bidan Desa dan Kelurahan Siaga Aktif berstrata Puri dengan belum Puri di Kabupaten Lumajang Tahun 2018.

Tabel 2. Masa Kerja Bidan Desa

\begin{tabular}{|c|c|c|c|c|c|}
\hline \multirow{3}{*}{ Masa Kerja } & \multicolumn{4}{|c|}{$\begin{array}{c}\text { Strata Desa dan } \\
\text { Kelurahan Siaga } \\
\text { Aktif }\end{array}$} & \multirow{3}{*}{$\begin{array}{c}p- \\
\text { value }\end{array}$} \\
\hline & \multicolumn{2}{|c|}{$\begin{array}{c}\text { Belum } \\
\text { Puri }\end{array}$} & \multicolumn{2}{|c|}{ Puri } & \\
\hline & $\mathbf{N}$ & $\%$ & $\mathbf{N}$ & $\%$ & \\
\hline$<10$ tahun & 31 & 68,9 & 14 & 31,1 & \\
\hline 10-20 tahun & 38 & 79,2 & 10 & 20,8 & 0483 \\
\hline$>20$ tahun & 16 & 69,6 & 7 & $\begin{array}{c}30, \\
4\end{array}$ & \\
\hline
\end{tabular}

Berdasarkan tabel 3 dapat diketahui $p$ value domisili 0,546 atau $>(0,05)$, maka keputusannya terima Ho atau tidak terdapat perbedaan antara domisili bidan Desa dan Kelurahan Siaga Aktif berstrata Puri dengan belum Puri di Kabupaten Lumajang Tahun 2018.

Tabel 3. Domisili Bidan Desa

\begin{tabular}{lccccc}
\hline \multirow{5}{*}{ Domisili } & \multicolumn{4}{c}{$\begin{array}{c}\text { Strata Desa dan } \\
\text { Kelurahan Siaga }\end{array}$} \\
& \multicolumn{2}{c}{$\begin{array}{c}\text { Aktif } \\
\text { Belum }\end{array}$} & Puri & p-value \\
& Puri & \% & N & \% & \\
\hline Tidak & 18 & 78,3 & 5 & 21,7 & 0 \\
Ya & 67 & 72,0 & 26 & 28,0 & 0,546 \\
\hline
\end{tabular}

Berdasarkan tabel 4 dapat diketahui $p$ value 0,756 atau $>\quad(0,05)$, maka keputusannya terima Ho atau tidak terdapat perbedaan antara motivasi intrinsik bidan Desa dan Kelurahan Siaga Aktif berstrata
Puri dengan belum Puri di Kabupaten Lumajang tahun 2018.

Tabel 4 Motivasi Intrinsik Bidan Desa

\begin{tabular}{lccccc} 
& \multicolumn{4}{c}{$\begin{array}{c}\text { Strata Desa dan } \\
\text { Kelurahan Siaga }\end{array}$} \\
Motivasi & \multicolumn{4}{c}{ Aktif } & $p$-value \\
intrinsik & \multicolumn{2}{c}{$\begin{array}{c}\text { Belum } \\
\text { Puri }\end{array}$} & Puri & \\
& N & $\%$ & N & \% & \\
\hline Rendah Sedang & 12 & 80 & 3 & 20 & 0,756 \\
Tinggi & 73 & 72,3 & 28 & 27,7 & \\
\hline
\end{tabular}

Berdasarkan tabel 5 dapat diketahui p-value 0,725 atau > $(0,05)$, maka keputusannya terima Ho atau tidak terdapat perbedaan antara motivasi ekstrinsik bidan Desa dan Kelurahan Siaga Aktif berstrata Puri dengan belum Puri di Kabupaten Lumajang tahun 2018.

Tabel 5. Motivasi Ekstrinsik Bidan Desa

\begin{tabular}{lccccc}
\hline \multicolumn{5}{c}{ Strata Desa dan } \\
Motivasi & \multicolumn{4}{c}{ Kelurahan Siaga } \\
Ekstrinsik & \multicolumn{2}{c}{$\begin{array}{c}\text { Belum } \\
\text { Puri } \\
\end{array}$} & Puri & p-value \\
& N & $\%$ & N & $\%$ & \\
\hline $\begin{array}{l}\text { Rendah } \\
\text { Sedang }\end{array}$ & 9 & 81,8 & 2 & 18,2 & \\
Tinggi & 76 & 72,4 & 29 & 27,6 & 0,725 \\
\hline
\end{tabular}

Berdasarkan tabel 6 dapat diketahui $p$-value 0,000 atau $<(0,05)$, maka keputusannya tolak Ho atau terdapat perbedaan antara sarana dan prasarana bidan Desa dan Kelurahan Siaga Aktif berstrata Puri dengan belum Puri di Kabupaten Lumajang Tahun 2018.

Tabel 6. Sarana dan Prasarana Bidan Desa

\begin{tabular}{lccccc}
\hline & \multicolumn{3}{c}{$\begin{array}{c}\text { Strata Desa dan } \\
\text { Kelurahan Siaga }\end{array}$} & \\
\cline { 2 - 5 } $\begin{array}{l}\text { Sarana dan } \\
\text { Prasarana }\end{array}$ & \multicolumn{3}{c}{$\begin{array}{c}\text { Aktif } \\
\text { Belum }\end{array}$} & Puri & value \\
& Puri & & & & \\
\cline { 2 - 5 } & $\mathbf{N}$ & $\mathbf{\%}$ & $\mathbf{N}$ & $\mathbf{\%}$ & \\
\hline Kurang lengkap & 85 & 95,5 & 4 & 4,5 & 0,000 \\
Lengkap & 0 & 0 & 27 & 100 & \\
\hline
\end{tabular}

Berdasarkan tabel 7 dapat diketahui $p$-value 0,004 atau $<(0,05)$, maka keputusannya tolak Ho atau terdapat perbedaan antara pelatihan bidan Desa Siaga Aktif berstrata Puri dengan belum Puri di Kabupaten Lumajang Tahun 2018. 
Tabel 7. Pelatihan Bidan Desa

\begin{tabular}{|c|c|c|c|c|c|}
\hline \multirow{3}{*}{ Pelatihan } & \multicolumn{4}{|c|}{$\begin{array}{c}\text { Strata Desa dan } \\
\text { Kelurahan Siaga } \\
\text { Aktif }\end{array}$} & \multirow{3}{*}{$\begin{array}{c}p- \\
\text { value }\end{array}$} \\
\hline & \multicolumn{2}{|c|}{$\begin{array}{c}\text { Belum } \\
\text { Puri }\end{array}$} & \multicolumn{2}{|c|}{ Puri } & \\
\hline & $\mathbf{N}$ & $\%$ & $\mathbf{N}$ & $\%$ & \\
\hline Tidak Pernah & 45 & 86,5 & 7 & 13,5 & \multirow{2}{*}{0,004} \\
\hline Pernah & 40 & 62,5 & 24 & 37,5 & \\
\hline
\end{tabular}

Berdasarkan tabel 8 dapat diketahui $p$ value 0,660 atau $>(0,05)$, maka keputusannya terima Ho atau tidak terdapat perbedaan antara supervisi bidan Desa dan Kelurahan Siaga Aktif berstrata Puri dengan belum Puri di Kabupaten Lumajang Tahun 2018.

Tabel 8. Supervisi Bidan Desa

\begin{tabular}{|c|c|c|c|c|c|}
\hline \multirow{3}{*}{ Supervisi } & \multicolumn{4}{|c|}{$\begin{array}{c}\text { Strata Desa dan } \\
\text { Kelurahan Siaga } \\
\text { Aktif }\end{array}$} & \multirow{3}{*}{$\begin{array}{c}p- \\
\text { value }\end{array}$} \\
\hline & \multicolumn{2}{|c|}{$\begin{array}{c}\text { Belum } \\
\text { Puri }\end{array}$} & \multicolumn{2}{|c|}{ Puri } & \\
\hline & $\mathbf{N}$ & $\%$ & $\mathbf{N}$ & $\%$ & \\
\hline Kurang & 7 & 77,8 & 2 & 22,2 & \\
\hline Cukup & 34 & 77,3 & 10 & 22,7 & 0,660 \\
\hline Baik & 44 & 69,8 & 19 & 30,2 & \\
\hline
\end{tabular}

Berdasarkan Tabel 9 dapat diketahui $p$ value 0,000 atau $<(0,05)$, maka keputusannya tolak Ho atau terdapat perbedaan antara dukungan masyarakat di Desa dan Kelurahan Siaga Aktif berstrata Puri dengan belum Puri di Kabupaten Lumajang Tahun 2018.

Tabel 9. Dukungan Masyarakat

\begin{tabular}{lrrrrr}
\hline \multicolumn{5}{c}{$\begin{array}{c}\text { Strata Desa dan } \\
\text { Kelurahan Siaga }\end{array}$} \\
Dukungan & \multicolumn{4}{c}{ Aktif } & \\
Masyarakat & $\begin{array}{c}\text { Belum } \\
\text { Puri }\end{array}$ & Puri & p-value \\
& N & \% & N & \% & \\
\hline Tidak Ada & 85 & 87,6 & 12 & 12,4 & 0 \\
Ada & 0 & 0,0 & 19 & 100 & 0,000 \\
\hline
\end{tabular}

Berdasarkan tabel 10 dapat diketahui $p$ value sebesar 0,726 atau $>(0,05)$, maka keputusannya terima Ho atau tidak terdapat perbedaan antara kinerja bidan Desa dan Kelurahan Siaga Aktif berstrata Puri dengan belum Puri di Kabupaten Lumajang tahun 2018.
Tabel 10. Kinerja

\begin{tabular}{|c|c|c|c|c|c|}
\hline \multirow{4}{*}{ Kinerja } & \multicolumn{4}{|c|}{$\begin{array}{c}\text { Strata Desa dan } \\
\text { Kelurahan Siaga Aktif }\end{array}$} & \multirow[t]{4}{*}{ p-value } \\
\hline & \multicolumn{2}{|c|}{$\begin{array}{l}\text { Belum } \\
\text { Puri }\end{array}$} & \multicolumn{2}{|c|}{ Puri } & \\
\hline & & & & $\%$ & \\
\hline & $\mathbf{N}$ & $\%$ & $\mathbf{N}$ & & \\
\hline $\begin{array}{l}\text { Kurang } \\
\text { Cukup }\end{array}$ & 7 & 70 & 3 & 30 & 0,726 \\
\hline Baik & 78 & 73,6 & 28 & 26,4 & \\
\hline
\end{tabular}

\section{Pembahasan}

Perbedaan Pengetahuan Bidan dalam Mengelola Desa dan Kelurahan Siaga Aktif Berstrata Puri dengan Belum Puri di Kabupaten Lumajang tahun 2018

Hasil analisis bahwa tidak terdapat perbedaan antara pengetahuan bidan Desa dan Kelurahan Siaga Aktif berstrata Puri dengan belum Puri di Kabupaten Lumajang tahun 2018. Hasil penelitian ini tidak sejalan dengan hasil penelitian yang menyatakan bahwa ada hubungan antara pengetahuan dengan kinerja bidan (Ainy, 2016). Penelitian ini juga tidak sesuai dengan teori yang dikemukakan oleh Gibson et al. (2015), yang menyatakan bahwa pengetahuan dapat memberi pengaruh untuk tingkat prestasi individu dalam melakukan pekerjaannya.

Perbedaan hasil penelitian ini dengan teori dan penelitian sebelumnya terjadi karena pengetahuan bidan Desa dan Kelurahan Siaga Aktif Puri dan belum Puri dalam mengelola Desa dan Kelurahan Siaga Aktif sebagian besar pada kategori tinggi. Pengetahuan bidan dalam mengelola Desa dan Kelurahan Siaga Aktif yang mayoritas tinggi dapat berasal dari kurikulum pelatihan yang telah diikuti bidan. Kurikulum disusun untuk meningkatkan pengetahuan dan kemampuan bidan sebagai pengelola Poskesdes yang merupakan sarana kesehatan bersumber daya masyarakat dan sebagai penyedia pelayanan kesehatan dasar bagi masyarakat dalam upaya mewujudkan Desa dan Kelurahan Siaga Aktif (Depkes RI, 2012) Penelitian ini didukung oleh hasil penelitian Kusrini (2012) menyatakan bahwa bidan secara teknis memiliki pengetahuan tentang pengelolaan Desa Siaga artinya mengetahui apa yang harus dikerjakan namun belum semua mengerjakan apa yang diketahuinya. 
Perbedaan Masa Kerja Bidan Dalam Mengelola Desa dan Kelurahan Siaga Aktif Berstrata Puri dengan Belum Puri di Kabupaten Lumajang Tahun 2018

Hasil analisis bahwa tidak terdapat perbedaan antara masa kerja bidan Desa dan Kelurahan Siaga Aktif berstrata Puri dengan belum Puri di Kabupaten Lumajang Tahun 2018. Penelitian ini berbeda dengan teori yang dikemukakan oleh Gibson et al. (2015), yang menyatakan bahwa lamanya masa tugas dan mengelola kasus berhubungan dan berpengaruh terhadap keterampilan seseorang. Penelitian ini berbeda dengan penelitian yang dilakukan oleh Suhrawadi (2015) yang menyimpulkan bahwa ada hubungan yang bermakna antara lama kerja dengan kinerja bidan dalam pelaksanaan Desa Siaga.

Perbedaan hasil penelitian ini dengan teori dan penelitian sebelumnya terjadi karena tidak selalu seseorang yang memiliki pengalaman atau masa kerja yang lama dalam melaksanakan suatu pekerjaan akan memiliki kinerja yang baik. Hal ini didukung oleh Surani (2008), yang menyatakan bahwa masa kerja juga tidak berhubungan dengan kinerja seseorang, semakin senior seorang pekerja bukanlah berarti akan lebih baik kinerjanya dibandingkan pada pekerja yang senioritasnya lebih rendah.

Perbedaan Variabel Domisili Bidan dalam Mengelola Desa dan Kelurahan Siaga Aktif Berstrata Puri dengan Belum Puri di Kabupaten Lumajang Tahun 2018

Hasil analisis bahwa tidak terdapat perbedaan antara domisili bidan Desa dan Kelurahan Siaga Aktif berstrata Puri dengan belum Puri di Kabupaten Lumajang Tahun 2018. Penelitian ini berbeda dengan teori yang dikemukakan oleh Gibson yang menyatakan bahwa tempat tinggal atau domisili merupakan faktor demografi yang mempengaruhi prestasi seseorang (Gibsonet al., 2015). Penelitian ini juga berbeda dengan penelitian Kristinawati (2011) menyatakan bahwa ada hubungan antara tempat tinggal bidan di desa dengan kinerja bidan di desa.

Perbedaan hasil penelitian ini dengan teori dan penelitian sebelumnya terjadi karena sebagian besar bidan, baik bidan Desa dan Kelurahan Siaga Aktif Puri dan belum Puri telah berdomisili di wilayah kerjanya, sehingga data yang diperoleh tidak bervariasi. Sesuai dengan teori yang menuliskan bahwa tenaga kesehatan yang menyelenggarakan pelayanan di Poskesdes minimal seorang bidan serta diharapakan tenaga kesehatan yang akan membantu Poskesdes berdomisili di desa/kelurahan setempat (Kementeriaan Kesehatan, 2012).

Perbedaan Variabel Psikologi (Motivasi Intrinsik dan Ekstrinsik) Bidan dalam Mengelola Desa dan Kelurahan Siaga Aktif Berstrata Puri Dengan Belum Puri di Kabupaten Lumajang Tahun 2018

a. Motivasi Intrinsik

Hasil analisis bahwa tidak terdapat perbedaan antara motivasi instrinsik bidan Desa dan Kelurahan Siaga Aktif berstrata Puri dengan belum Puri di Kabupaten Lumajang Tahun 2018. Penelitian ini berbeda dengan penelitian Ainy (2016) menyatakan bahwa motivasi berhubungan positif dengan kinerja bidan. Penelitian ini juga berbeda dengan teori yang dikemukakan oleh Azwar (2010) yang menyatakan bahwa motivasi merupakan salah satu dari faktor psikologis yang dapat mempengaruhi kinerja.

Perbedaan hasil penelitian ini dengan teori dan penelitian sebelumnya karena mayoritas bidan desa baik bidan Desa dan Kelurahan Siaga Aktif berstrata Puri dan belum Puri memiliki motivasi yang tinggi dalam mengelola program Desa dan Kelurahan Siaga Aktif. Menurut Kusrini (2012), motivasi bidan yang baik diperlukan dalam pengelolaan program Desa Siaga sebab dengan adanya motivasi akan mendorong bidan di desa melakukan upaya agar wilayah kerjanya menjadi Desa/Kelurahan Siaga Aktif. Menurut peneliti tidak bermaknanya motivasi dengan kinerja bidan desa dalam mengelola program Desa dan Kelurahan Siaga Aktif di Kabupaten Lumajang dapat disebabkan Karena bidan merasa telah puas dengan kinerjanya jika desa wilayah kerjanya sudah berstatus Aktif meskipun stratanya belum Puri.

b. Motivasi Ekstrinsik

Hasil analisis bahwa tidak terdapat perbedaan antara motivasi ekstrinsik bidan Desa dan 
Kelurahan Siaga Aktif berstrata Puri dengan belum Puri di Kabupaten Lumajang Tahun 2018. Penelitian ini berbeda dengan penelitian Ainy (2016) menyatakan bahwa motivasi berhubungan dengan kinerja bidan. Penelitian ini juga berbeda dengan teori yang dikemukakan oleh Azwar (2010) yang menyatakan bahwa motivasi merupakan salah satu dari faktor psikologis yang dapat mempengaruhi kinerja.

Perbedaan hasil penelitian ini dengan teori dan penelitian sebelumnya karena mayoritas bidan desa, baik bidan Desa dan Kelurahan Siaga Aktif berstrata Puri dan belum Puri memiliki motivasi yang tinggi dalam mengelola program Desa dan Kelurahan Siaga Aktif. Menurut Kusrini (2012), motivasi bidan yang baik diperlukan dalam pengelolaan program Desa Siaga sebab dengan adanya motivasi akan mendorong bidan di desa melakukan upaya agar wilayah kerjanya menjadi Desa/Kelurahan Siaga Aktif. Menurut peneliti tidak bermaknanya motivasi dengan kinerja bidan desa dalam mengelola program Desa dan Kelurahan Siaga Aktif di Kabupaten Lumajang dapat disebabkan tidak adanya reward bagi bidan di desa dan kelurahan yang telah mewujudkan wilayah kerjanya menjadi Desa dan Kelurahan Siaga Aktif berstrata Puri dan tidak adanya sanksi yang akan diterima oleh bidan desa atas kinerja mereka selama bertanggungjawab mengelola Desa dan Kelurahan Siaga Aktif belum Puri (Kemenkes RI, 2010).

Perbedaan Variabel Sarana dan Prasarana Bidan dalam Mengelola Desa Siaga Aktif Berstrata Puri dengan Belum Puri di Kabupaten Lumajang Tahun 2018

Hasil analisis bahwa terdapat perbedaan antara sarana dan prasarana bidan Desa dan Kelurahan Siaga Aktif berstrata Puri dengan belum Puri di Kabupaten Lumajang Tahun 2018. Hasil penelitian ini sejalan dengan penelitian yang dilakukan Tetelepta (2011) menyebutkan program Desa Siaga belum terlaksana maksimal, salah satunya disebabkan sarana dan prasarana masih bergantung pada bantuan pemerintah (Telepta, 2011). Berbeda dengan hasil penelitian oleh Andriani (2012) yang menyimpulkan bahwa tidak ada hubungan antara sarana dan prasarana dengan kinerja bidan di desa (Andriani, 2012).

Perbedaan hasil penelitian ini dengan penelitian sebelumnya terjadi karena memang seharusnya bidan di desa memiliki sarana dan prasarana kerja yang lengkap untuk mendukung kinerjanya, seperti teori yang menyebutkan bahwa dalam penyelenggaraan Pos Kesehatan Desa diperlukan tempat pelayanan dalam pelaksanaan pelayanan kesehatan di dalam poskesdes, diperlukan ruangan dan gedung poskesdes, peralatan (perlatan medis dan peralatan non medis) dan obat-obatan (Depkes RI, 2012).

Perbedaan Variabel Pelatihan Bidan dalam Mengelola Desa dan Kelurahan Siaga Aktif Berstrata Puri dengan Belum Puri di Kabupaten Lumajang Tahun 2018

Hasil analisis bahwa terdapat perbedaan antara pelatihan bidan Desa dan Kelurahan Siaga Aktif berstrata Puri dengan belum Puri di Kabupaten Lumajang Tahun 2018. Hasil penelitian ini sejalan dengan penelitian yang dilakukan oleh Suhrawardi et al. (2014) yang menyatakan bahwa ada hubungan yang bermakna antara pelatihan Desa Siaga dengan kinerja bidan dalam pelaksanan kegiatan Desa Siaga $^{[9]}$.

Pelatihan program Desa Siaga merupakan bekal pengetahuan dan keterampilan bidan untuk melaksanakan kegiatan Desa dan Keluraan Siaga Aktif (Depkes RI, 2012). Untuk itu pelatihan perlu diikuti oleh semua bidan yang bekerja pada Desa dan Kelurahan Siaga Aktif agar mereka mempunyai pengetahuan dan keterampilan tentang kegiatankegiatan yang dilaksanakan pada program Desa dan Kelurahan Siaga Aktif.

Perbedaan Variabel Supervisi dalam Mengelola Desa dan Kelurahan Siaga Aktif Berstrata Puri dengan Belum Puri di Kabupaten Lumajang Tahun 2018

Hasil analisis bahwa tidak terdapat perbedaan antara supervisi Desa dan Kelurahan Siaga Aktif berstrata Puri dengan belum Puri di Kabupaten Lumajang Tahun 2018. Hasil penelitian ini sejalan dengan penelitian yang dilakukan oleh Kusrini (2012) yang menyatakan bahwa tidak terdapat hubungan yang bermakna antara supervisi dengan kinerja bidan di desa dalam mengelola program 
Desa Siaga (Kusrini, 2012). Berbeda dengan penelitian yang dilakukan oleh Ainy (2016) menyatakan bahwa supervisi berhubungan dengan kinerja bidan (Gibson, et. al., 2015).

Tidak adanya perbedaan yang bermakna supervisi dalam mengelola Desa dan Kelurahan Siaga Aktif berstrata Puri dengan belum Puri menurut pengalaman peneliti kemungkinan supervisi tersebut tidak memberikan manfaat yang besar terhadap masalah yang dihadapi oleh bidan di desa berkaitan dengan pengelolaan program Desa Siaga. Sehingga tidak berpengaruh terhadap strata Desa dan Kelurahan Siaga Aktif. Hal ini didukung oleh Ainy (2016) dalam pelaksanaan supervisi harus memperhatikan unsur-unsur supervisi sehingga bisa memberikan manfaat (Gibson, et. al., 2015).

Perbedaan Variabel Dukungan Masyarakat dalam Mengelola Desa dan Kelurahan Siaga Aktif Berstrata Puri dengan Belum Puri di Kabupaten Lumajang Tahun 2018

Hasil analisis bahwa terdapat perbedaan antara dukungan masyarakat Desa dan Kelurahan Siaga Aktif berstrata Puri dengan belum Puri di Kabupaten Lumajang Tahun 2018. Penelitian ini berbeda dengan penelitian yang dilakukan oleh Kristinawati (2011) yang menyatakan bahwa tidak ada hubungan antara dukungan masyarakat dengan kinerja bidan (Kristinawati, 2011). Penelitian ini berbeda dengan penelitian sebelumnya karena kinerja bidan di desa berhubungan erat dengan dukungan masyarakat karena inti dari Desa dan Kelurahan Siaga Aktif adalah pemberdayaan masyarakat, dukungan tokoh-tokoh masyarakat khususnya bertujuan dalam membentuk opini publik guna menciptakan iklim yang kondusif bagi pengembangan Desa dan Kelurahan Siaga Aktif (Depkes RI, 2012).

Hasil penelitian ini sejalan dengan penelitian yang dilakukan oleh Guswanti (2008) bahwa ada perbedaan bermakna antara dukungan masyarakat dengan kinerja bidan di desa dalam mengelola program desa siaga. Menurut peneliti, hubungan dukungan masyarakat dengan kinerja bidan desa bermakna karena untuk mewujudkan Desa dan Kelurahan Siaga Aktif berstrata Puri memang sangat dibutuhkan peran serta masyarakat serta dukungan dari masyarakat.

Perbedaan Kinerja Bidan dalam Mengelola Desa dan Kelurahan Siaga Aktif Berstrata Puri dengan Belum Puri di Kabupaten Lumajang Tahun 2018

Hasil analisis bahwa tidak terdapat perbedaan antara kinerja bidan Desa dan Kelurahan Siaga Aktif berstrata Puri dengan belum Puri di Kabupaten Lumajang Tahun 2018. Menurut peneliti tidak terdapat perbedaan kinerja bidan dalam mengelola Desa Siaga Aktif berstrata Puri dengan belum Puri karena bidan sudah melaksanakan tugasnya sesuai dengan kompetensi bidan dalam pengembangan Desa Siaga.

Hasil penelitian ini sejalan dengan penelitian yang dilakukan oleh Farid (2013) bahwa tidak terdapat perbedaan bermakna antara kinerja bidan desa yang bertugas di desa Siaga Aktif pratatama, madya, purnama dan mandiri, yang berarti semakin tinggi tingkatan desa siaga aktif tidak selalu meningkatkan kinerja bidan yang bertugas di desa tersebut (Farid, 2013). Farid (2013) menyatakan bahwa bidan bukanlah satu-satunya faktor yang mempengaruhi keberhasilan program Desa Siaga, akan tetapi ada pihak-pihak lain yang harus dilibatkan.

\section{KESIMPULAN DAN SARAN}

Kesimpulan dari penelitian ini adalah terdapat perbedaan sarana dan prasarana, pelatihan, dukungan masyarakat antara bidan Desa dan Kelurahan Siaga Aktif berstrata Puri. Dengan belum Puri. Dan tidak ada perbedaan pengetahuan, masa kerja, domisili, motivasi intrinsik, motivasi ekstrinsik, supervisi, kinerja antara bidan Desa dan Kelurahan Siaga Aktif berstrata Puri dengan belum Puri.

Saran dari penelitian ini adalah Bagi Dinas Kesehatan yaitu mempertahankan reward berupa uang pembinaan yang diberikan kepada Desa dan Kelurahan Siaga Aktif berstrata Puri, memberikan pelatihan kepada bidan Desa dan Kelurahan Siaga Aktif berstrata belum Puri. Bagi Puskesmas yaitu memberikan pembinaan secara periodik, intensif dan terarah oleh bidan koordinator maupun petugas promosi kesehatan kepada bidan Desa dan Kelurahan Siaga Aktif belum Puri serta diharapkan meninjau secara intensif terhadap kelengkapan sarana dan prasarana.Bagi Bidan yaitu bidan Desa 
dan Kelurahan Siaga Aktif belum Puri berusaha mengikuti pelatihan untuk mewujudkan Desa dan Kelurahan Siaga Aktif berstrata Puri, bidan Desa dan Siaga Aktif belum Puri perlu melakukan advokasi kepada Kepala Desa dan Badan Perwakilan Desa (BPD) agar ada kebijakan pengalokasian dana dalam rangka pembangunan gedung poskesdes atau memanfaatkan bangunan yang tidak terpakai untuk gedung Poskesdes.

\section{DAFTAR PUSTAKA}

1] Undang-Undang RI No 36. (2009) Kesehatan. Jakarta.

2] Keputusan Menteri Kesehatan RI No 1529. (2010) Pedoman Umum Pengembangan Desa dan Kelurahan Siaga Aktif. Jakarta: Pusat Promosi Kesehatan.

3] Dinkes Jatim. (2017) Data Desa Siaga Provinsi Jawa Timur Tahun 2017. Surabaya: Dinkes Jatim.

4] Dinas Kesehatan Kabupaten Lumajang. (2017) Data Desa Siaga di Lumajang Tahun 2017. Lumajang: Dinkes Lumajang.

5] Ainy, Q. (2016) Analisis Faktor yang Berhubungan dengan Kinerja Bidan dalam Pelayanan Antenatal Care di Wilayah Puskesmas Kabupaten Jember Tahun 2015. Skripsi. Jember: Fakultas Kesehatan Masyarakat :Universitas Jember.

https://repository.unej.ac.id/bitstream/ha ndle/123456789/77246/Qurrotul\%20Ain y.pdf?sequence $=1$ [3 Maret 2019]

6] Gibson, J.L., Ivancevich, J. M., dan Donnelly, J. H. (2015) Organisasi: Perilaku, Struktur, Proses Edisi Kelima Terjemahan. Erlangga: Jakarta.

7] Departemen Kesehatan, RI. (2012) Kurikulum Petunjuk Teknis Pengembangan dan Penyelenggaraan Pos Kesehatan Desa. Jakarta.

8] Kusrini. (2012) Studi Kinerja Bidan di Desa dalam Mengelola Program Desa Siaga di Kabupaten Kebumen Tahun 2012. Skripsi. Depok: Universitas
Indonesia. https://digital 20321671-SKusrini.pdf [21 Juni 2018]

9] Suhrawadi., Vonny K.D., Norlena. (2015) Faktor-Faktor yang Berhubungan dengan Kinerja Bidan dalam Pelaksanaan Kegiatan Desa Siaga di Kabupaten Tapin. Jurnal Skala Kesehatan. Vol.6, No.2 Halaman 111.Banjarmasin: Poltekkes Kemenkes http://ejurnalskalakesehatan-

poltekkesbjm.com/index.php/JSK/article/view/ 41 [21 Juni 2018]

10] Surani, E. (2008) Analisis Karakteristik Individu dan Faktor Intrinsik yang Berhubungan dengan Kinerja Bidan Desa Pelaksana Polikilinik Kesehatan Desa dalam Pelayanan Kesehatan Dasar di Kabupaten Kendal. Skripsi. Semarang: Universitas Diponegoro.https://core.ac.uk/download/pdf/11 717121.pdf [21 Juni 2018]

11] Kristinawati,D. (2011) Faktor-Faktor yang Berhubungan dengan Kinerja Bidan Desa di Kabupaten Bntul Daerah Istimewa Yogyakarta. Skripsi Depok: Universitas Indonesia.https://digital_2016-12_20440778Dina Kristinawati.pdf [20 Maret 2019]

12] Departemen Kesehatan, RI. (2012) Kurikulum Petunjuk Teknis Pengembangan dan Penyelenggaraan Pos Kesehatan Desa. Jakarta.

13] Azwar, A. (2010) Pengantar Administrasi Kesehatan. Jakarta: Binarupa Aksara.

14] Kemenkes RI dan Kemendagri RI. (2010) Pedoman Umum Pengembangan Desa dan Kelurahan Siaga Aktif dalam Rangka Akselerasi Program Pengembangan Desa Siaga. Jakarta: Katalog dalam Terbitan Kementerian Kesehatan RI.

15] Tetelepta, D. (2011) Implementasi Program Desa Siaga di Tinjau dari Perspektif Provider di Wilayah Kerja Puskesmas Layeni Kecamatan Teon Nila Serua Kabupaten Maluku Tengah. Skripsi. Semarang: Universitas Diponegoro. http://eprints.undip.ac.id/32622/ [21 Juni 2018]

16] Andriani, Y. (2012) Faktor-Faktor yang Berhubungan dengan Kinerja Bidan di Desa dalam Pelaksanaan Program Jaminan Persalinan Di Kabupaten Lampung Barat 
Tahun 2012. Skripsi.Depok: Universitas Indonesia.https:// digital 20318305-SYuliAndriani.pdf [20 Maret 2019]

17] Guswanti, E. (2008) Faktor-Faktor yang Berhubungan dengan Kinerja Bidan dalam Mengelola Desa Siaga di Kabupaten Ogan Ilir. Skripsi. Universitas Indonesia: Depok https:// digital 20339776-T32050-Erda Guswanti.pdf [21 Juni 2018]

18] Farid., Effendi J.S., Kristiyanti, R.Kinerja (2018) Bidan Desa pada Berbagai Tingkatan Desa Siaga Aktif di Kabupaten Pekalongan. Artikel Ilmiah. Universitas Padjajaran: Bandung. http://pustaka.unpad.ac.id/ wpcontent/uploads/2014/04/ARTIKEL RINI.pdf [21 Juni 2018] 